\title{
Cost-benefit analyses to assess the potential of Operational Earthquake Forecasting prior to a mainshock in Europe
}

\author{
John Douglas $^{1}$ (iD $\cdot$ Alireza Azarbakht ${ }^{1,2}$ (D)
}

Received: 26 May 2020 / Accepted: 5 September 2020 / Published online: 16 September 2020

(c) The Author(s) 2020

\begin{abstract}
In the past couple of decades, Operational Earthquake Forecasting (OEF) has been proposed as a way of mitigating earthquake risk. In particular, it has the potential to reduce human losses (injuries and deaths) by triggering actions such as reinforcing earthquake drills and preventing access to vulnerable structures during a period of increased seismic hazard. Despite the dramatic increases in seismic hazard in the immediate period before a mainshock (of up to 1000 times has been observed), the probability of a potentially damaging earthquake occurring in the coming days or weeks remains small (generally less than $5 \%$ ). Therefore, it is necessary to balance the definite cost of taking an action against the uncertain chance that it will mitigate earthquake losses. In this article, parametric costbenefit analyses using a recent seismic hazard model for Europe and a wide range of inputs are conducted to assess when potential actions for short-term OEF are cost-beneficial prior to a severe mainshock. Ninety-six maps for various combinations of input parameters are presented. These maps show that low-cost actions (costing less than $1 \%$ of the mitigated losses) are cost-beneficial within the context of OEF for areas of moderate to high seismicity in the Mediterranean region. The actions triggered by OEF in northern areas of the continent are, however, unlikely to be cost-beneficial unless very large increases in seismicity are observed or very low-cost actions are possible.
\end{abstract}

Keywords Time-dependent seismic hazard $\cdot$ Feasibility study $\cdot$ Risk mitigation actions · Nomogram $\cdot$ Decision making $\cdot$ Parametric analysis

Electronic supplementary material The online version of this article (https://doi.org/10.1007/s1106 9-020-04310-3) contains supplementary material, which is available to authorized users.

John Douglas

john.douglas@strath.ac.uk

1 Department of Civil and Environmental Engineering, University of Strathclyde, James Weir Building, 75 Montrose Street, Glasgow G1 1XJ, UK

2 Department of Civil Engineering, Faculty of Engineering, Arak University, P.O. Box 38156-8-8349, Arak, Iran 


\section{Introduction}

The purpose of this article is to assess, at a continental scale, the potential of Operational Earthquake Forecasting (OEF) for the mitigation of earthquake risk in Europe. For OEF to be useful, it needs to be able to trigger risk-mitigation actions (e.g. encourage citizens to reinforce earthquake drills, so they are better prepared in the case of a strong earthquake). OEF should aim at providing complete, authoritative, reliable and timely information before a mainshock (the focus of the current study) as well as during the aftershock period (excluded from consideration here). All actions should be recommended but not necessarily prescribed since political and psychological aspects must also be taken into consideration. The benefits of OEF and its procedures have been extensively discussed (Field et al. 2016; Marzocchi et al. 2014; Jordan et al. 2014; Cauzzi et al. 2016; Iervolino et al. 2015; Jordan and Jones 2010; Peresan et al. 2012; Sellnow et al. 2017; Christophersen et al. 2017; Jordan et al. 2011).

From a technical point of view, OEF works with the increase in the seismic hazard over a specific time window: short (days), moderate (weeks) or long (months or years) durations. Here we focus on short-term OEF, corresponding to between one week (7 days) and one month (30 days) before a mainshock. Therefore, the most important issue is whether (or, even, if) we should recommend a specific action based on the level of hazard increment before a mainshock and the set of short-term actions that are possible and feasible. Simple cost-benefit analyses based on the approach of Marzocchi and Woo (2009), Woo (2010) and Woo (2013) are conducted to assess where and under what conditions such actions would be cost-beneficial. Van Stiphout et al. (2010) conducted similar analyses for the 2009 L'Aquila earthquake to assess whether an evacuation of the population would have been cost-beneficial.

In the following section, the benefit-to-cost ratio is introduced, which is the basis of the approach used here. This section also includes a discussion of the assumptions and limitations of the approach. Following this, a brief review of the literature on the use of cost-benefit analyses to rank risk mitigation actions for natural hazards is provided. Next, the relevant inputs to the analyses are discussed, and some estimates of the key input parameters are made. The following section (and the electronic supplement) presents 96 maps for a range of input parameters. The penultimate section discusses the derivation of a nomogram to conduct the cost-benefit analyses. The final section presents some brief conclusions.

\section{Cost-benefit analysis for OEF}

The method used to assess the potential for OEF at a continental scale is based on the benefit-to-cost ratio, $R$, which is defined as, e.g. Marzocchi and Woo (2009), Woo (2010), Woo (2013):

$$
R=\frac{p L}{C}
$$

where $p$ is the probability, during a specific number of days $d$, of occurrence of a ground motion intensity measure (IM), e.g. peak ground acceleration, PGA, above a threshold with the potential to cause loss; and $C$ is the cost of taking an action that leads to a reduction of that loss by an amount $L$. In general, the action will not mitigate the entire loss but only a 
Table 1 Matrix of the possible costs and losses assumed within the cost-benefit analyses

\begin{tabular}{lll}
\hline & No action taken & Action taken \\
\hline IM $<$ threshold & 0 & $C$ \\
IM $\geq$ threshold & $L$ & $C$ \\
\hline
\end{tabular}

proportion of it. For example, if the action considered is an evacuation of a town then the total loss would include any structural damage that occurred, but this part of the loss would not have been mitigated by the action, only the loss associated with fatalities and injuries to the population evacuated (e.g. van Stiphout et al. 2010). In this article, we are only considering direct costs and losses related to the action and not indirect costs, e.g. long-term business implications, and losses, e.g. long-term environmental damage. A cost-beneficial action is one where $R>1$. Others (e.g. Brooks et al. 2016) use the net benefit to decide when an action is beneficial rather than the benefit-to-cost ratio. The break-even point in the two cases is the same, but the benefit-to-cost ratio is easier to understand and is more commonly used within the field of natural hazards (see below).

\subsection{Assumptions and limitations of the approach}

A complete cost-benefit analysis of OEF would not be straightforward, and it is acknowledged that the assumptions made in the following analyses are considerable. These analyses aim to provide easily understandable maps and results on which parts of Europe would potentially benefit from the installation and operation of OEF before a possible severe mainshock. Because of our wish to cover all of Europe and to be general (i.e. not for a specific type of infrastructure or city or seismic sequence), there is a need for considerable simplification.

The analyses below do not include the costs of installing and operating a system for OEF. Much of the required infrastructure (e.g. instruments, communication networks and personnel) are already operating over much of Europe as part of local, regional, national and international seismic monitoring programmes. Therefore, the additional cost of the monitoring part of OEF is likely to be marginal and also spread out over the continent, so it is not correct to include it within the costs of a specific forecast. Obtaining the funds for this additional cost might, however, still be controversial in some regions. There will be a cost to communicate the forecasts to the public and other stakeholders (a variety of stakeholders for OEF are listed in Table 2). This cost is not assessed here-again because it is likely to be minimal as communication channels through, e.g. radio, TV and the internet, already exist and are often used for hydro-meteorological hazards (e.g. floods). It is worth emphasising that to secure the public's trust, even poor communication may be better than silence as this shows respect for the public's right to know, even if they are informed clumsily (Fischhoff 2015).

It is usual in cost-benefit analyses to adjust the costs or benefits by a discount rate because they do not occur now but sometime in the future. In the case of short-term OEF, however, this adjustment is not required because of the short timescale considered (days to months) and the low inflation rates of European economies. The cost would be incurred now, and the loss avoided (benefit) would occur (or not) within the coming days or weeks.

One of the main assumptions of the approach is that the costs and losses mitigated are binary, i.e. either 0 or 1 . The matrix of the four possible costs and losses is shown in Table 1. This assumption is justified for the scale of the analyses considered here and our 
Table 2 Potential actions for OEF (e.g. Field et al. 2016)

\begin{tabular}{|c|c|}
\hline $\begin{array}{l}\text { Responsible } \\
\text { party/Stake- } \\
\text { holder }\end{array}$ & Potential actions \\
\hline General public & $\begin{array}{l}\text { Checking food, water, medical supplies; having cash on hand; keeping phones charged and } \\
\text { fuel in the car; reviewing family emergency plans; securing household objects }\end{array}$ \\
\hline Private sector & $\begin{array}{l}\text { Insurance/banks/industry advisory; securing business premises; relocating business } \\
\text { premises; relocating employees to other branches of the business; activating structural } \\
\text { control systems }\end{array}$ \\
\hline Public sector & $\begin{array}{l}\text { Assuring smooth operation of important infrastructure, hospitals, police, mobile phone } \\
\text { network, etc.; checking emergency plans/monitoring systems; reinforcing earthquake } \\
\text { drills; school/hospital/transportation/police/ services advisory; conditioning earthquake } \\
\text { early warning systems to expect future earthquakes in regions of increased seismic } \\
\text { activity; checking the town for dangerous non-structural elements (e.g. flower pots and } \\
\text { shop signs) and removing them; require the evacuation of vulnerable buildings; require } \\
\text { sleeping outside; restrict travel to an area with elevated hazard; evacuating people to } \\
\text { areas where the hazard is not elevated }\end{array}$ \\
\hline
\end{tabular}

wish for the analyses to have general applicability. To use a more sophisticated loss model (e.g. a lognormal distribution used for vulnerability curves) or cost models would require specific actions and elements at risk to be considered.

Fiore et al. (2019) provide a justification for the use of Eq. 1 to conduct cost-benefit analyses. They find that the same formula provides a good first approximation to a more complete expression when: (a) the discount rate is low, (b) the period of consideration is short and (c) the rates of failure (before and after the action is taken) are also low. All of these are valid assumptions for short-term OEF given the actions that can be envisioned within the intervals of interest. By using Eq. 1, we are assuming that the rate of failure (loss) after the action is taken zero or more generally much less than the rate of failure (loss) if that action had not been taken.

In the following, PGA is used as the single IM within the calculations. This assumes that it is the most appropriate description of the earthquake ground motions that could cause a loss that is reducible by taking an action associated with OEF. This is obviously not true as many studies have shown that IMs such as response spectral accelerations at the fundamental period of a structure or peak ground velocity are more appropriate in many situations. PGA was chosen, however, as it is a readily understood parameter for communication with end-users. PGA is also reasonably well correlated with macroseismic intensity (e.g. Caprio et al. 2015), which means the use of PGA roughly captures the damage potential of earthquake ground motions. Finally, because of the relatively strong correlation between other measures of the amplitude of earthquake ground motions (e.g. Arias intensity, peak ground velocity and short-period response spectral accelerations) and PGA (e.g. Baker and Bradley 2017), it is likely that using one of these other IMs would lead to similar conclusions.

A fundamental assumption in the following calculations is that cost-benefit analyses are a good model for how people make (or should make) decisions. Cost-benefit analyses have a long history in choosing which risk mitigation actions should be funded, although often the results are used to guide, rather than make, decisions. A brief discussion of cost-benefit analyses in this context is provided in the following section. Wanigarathna and Yarovaya (2018) provide a useful overview of this topic, including a discussion of the various costs and benefits that should be considered in more detailed analyses. It is worth noting that 
judging the usefulness of OEF is not limited to use of cost-benefit analysis. OEF can be justified by other approaches as well. Different stakeholders can use the obtained OEF information based on their understanding of the situation and their policies.

\subsection{Cost-benefit analyses for natural hazards}

A useful recent review of cost-benefit analyses for risk mitigation is by Mechler (2016) who reports that $\mathrm{R}$ for earthquake risk mitigation actions ranges from 0.08 to 15.6 (average of 3.0) from eight identified studies, which is lower than the average of 4.6 (range 0.1-30) from 21 studies on flood risk mitigation but slightly higher than the average of 2.6 (range 0.05-50) from 7 studies on risk mitigation for extreme winds. An excellent summary of the results of over a hundred cost-benefit analyses for natural hazards (floods, landslides, earthquakes, droughts, storms and combinations of hazards) is provided by Hugenbusch and Neumann (2016). They identify 11 studies conducting cost-benefit analyses for earthquakes. In almost all cases, the mitigation actions were "structural" (e.g. retrofitting of vulnerable buildings) rather than "non-structural" (e.g. knowledge transfer, capacity building and codes/norms, such as land-use planning). In nine of these studies for earthquakes, actions were not assessed as cost-beneficial either in whole or in part. Hugenbusch and Neumann (2016) find when considering all natural hazards together that non-structural actions are often more cost-beneficial. Godschalk et al. (2009), who summarise benefit-tocost ratios for projects funded by the US Federal Emergency Management Agency, reached similar conclusions. They note that process grants (investments in human, social or institutional capital) for earthquake risk mitigation have an average ratio of 2.5 , which is higher than for wind (1.7) and flood (1.3) process grants, whereas project grants (investments in physical capital) for earthquake risk mitigation have an average ratio of 1.4 , which is much lower than for wind (4.7) and flood (5.1) project grants. As the actions possible for shortterm OEF would be classed as "non-structural" or "process grants", given the time available to take them, this finding is promising for OEF.

There have been a number of probabilistic cost-benefit analyses for retrofitting vulnerable structures against earthquakes. Examples of these include Smyth et al. (2004), Ghesquiere et al. (2006), Kunreuther and Michel-Kerjan (2012), Liel and Deierlein (2013), Wei et al. (2014) and references therein. These studies often find that extensive retrofitting is not cost-beneficial $(R<1)$ or is marginally cost-beneficial ( $R$ between 1 and 1.5) except for the most vulnerable structures and those with many inhabitants. Such calculations rely on extensive calculations using earthquake risk assessment software and detailed hazard and vulnerability inputs. As such they are unfeasible for this study because of the scale of the analysis (all Europe) and the need to be general about the type of mitigation actions considered. For earthquake risk, there are very few studies that conduct cost-benefit analyses for actions other than retrofitting buildings. Retrofitting is not possible to undertake in the context of short-term OEF because it would take longer to do than the period of heightened hazard will likely last. A recent discussion of the issues surrounding the use of cost-benefit analyses for relatively short periods (weeks or months) of heightened hazard (in this case volcanic hazard) is provided by Woo (2015).

Brooks et al. (2016) conduct simple cost-benefit analyses to assess whether a water heater should be secured against earthquake shaking. They concluded that for areas of low seismic hazard, such as Chicago, that this action is not beneficial but that in areas of higher seismic hazard it could be. Strauss and Allen (2016) present some simple cost-benefit analyses for the operation of an earthquake early warning system for the west coast of 
the USA. The costs of this system were taken from a previous study, and the benefits were assessed in a simple way using losses from a variety of causes in recent earthquakes and based on simulations. There is little discussion on the probabilities associated with these potential losses. Holden et al. (1989), when studying the potential for an earthquake early warning system for California, find that there is too much uncertainty (based on the results of a survey of potential end-users) in the potential benefits of such a system to conduct a detailed cost-benefit analysis. They do, however, formulate the analysis in a similar way to proposed here, although they use the net benefit (rather than the benefit-to-cost ratio). Plag et al. (2014) use simple cost-benefit analysis (using Eq. 1) to estimate how much money should be invested per year worldwide to reduce the risk associated with extreme volcanic eruptions. (They estimate this total as several billion dollars per year.)

Cost-benefit analyses for short-term forecasts (often called "early warnings" in the literature) of other natural hazards (e.g. floods or extreme winds) often show benefit-to-cost ratios much larger than unity (i.e. they are clearly cost-beneficial) (e.g. Hallegatte 2012). Therefore, "early warning" has been recommended as a good way of mitigating risk in less developed countries (e.g. Copenhagen Consensus Center 2012). This is because the probability of the hazardous event occurring following a forecast is much higher, so costly actions such as evacuation (in case of a hurricane warning or flood) or construction of temporary protective works (e.g. sandbags to protect against floodwaters) become beneficial. The probabilities of potentially damaging earthquake ground motions from a mainshock occurring in a short interval following a forecast are small, even in periods of increased seismicity. Therefore, the costs of risk mitigation actions also need to be small to make them cost-beneficial.

\section{Assessment of the input parameters to the analyses}

In this section, potential risk mitigation actions that could be triggered by OEF are listed, the various input parameters to the cost-benefit analyses are discussed, and a range of plausible values for these input parameters is proposed.

\subsection{Potential actions and corresponding thresholds, losses and costs}

The above framework, as expressed in Eq. 1, is based on three principal variables: $p, L$ and $C$. The first variable, $p$, is an indicator of the real-time seismic hazard for the location considered (this is discussed in a subsequent section). $p$ is also a function of $d$, the number of days for which the action is implemented. Finally, $p$ is also a function of the threshold PGA (as noted above, only PGA is considered in these calculations): as the threshold PGA increases, $p$ decreases. The effect of changing the threshold PGA can be estimated by making use of the observation that seismic hazard curves typically follow a power law, which is discussed next. If $\mathrm{L} / \mathrm{C}$ remained the same, then a lower threshold would make the mitigation actions appear more beneficial and vice versa for a higher threshold.

Seismic hazard curves can often be parameterised using a power law, i.e.: $H(y)=k_{0} y^{-k 1}$, where $y$ is the value of the IM of interest (e.g. PGA), $H$ is the annual frequency of exceedance, and $k_{0}$ and $k_{1}$ are site-specific coefficients chosen to fit the hazard curve over the exceedance frequencies of interest. Therefore, assuming that annual frequency of exceedance and daily probabilities of exceedance are proportional (this is not strictly correct, but it is likely almost true for the ground-motions levels of interest here), there is roughly a 
one-to-one mathematical relationship between the daily probabilities of exceedance of two ground-motion levels. This relationship is given by: $\left(y_{2} / y_{1}\right)^{k 1}$, where $y_{1}$ is the lower groundmotion level, and $y_{2}$ is the higher ground-motion level. Figure 14 of Gkimprixis et al. (2019) shows that $k_{1}$ varies between 1.5 and 2.5 for much of Europe based on the European Seismic Hazard Model 2013 (ESHM 2013, Giardini et al. 2013; Woessner et al. 2015). Therefore, if for example, $y_{1}=0.05 \mathrm{~g}$ and $y_{2}=0.2 \mathrm{~g}$, then the ratio of the weekly probabilities of exceedance of these ground-motion levels would be between 8 and 32 .

The second and third variables within Eq. $1, L$ and $C$, are functions of the risk-mitigation actions that are considered in the analysis. Rather than using actual values of the loss and cost, it is easier and more general to use the ratio $L / C$. Therefore, this ratio is used from now on. Potential actions and corresponding $\mathrm{L} / \mathrm{C}$ values are discussed in the following section.

\subsection{Potential risk-mitigation actions}

Because of the relatively short periods for which OEF is likely to operate, only actions that can be taken quickly can be considered. Therefore, it is not possible to recommend structural retrofitting of vulnerable structures, for example, as this would take many weeks or months to put in place. In this section, some example actions are discussed.

The types of losses that the actions seek to mitigate are principally human losses, e.g. death, major and minor injuries that require hospitalisation and very minor injuries (e.g. cuts and bruises); damage to non-structural elements and building contents; and knock-on impacts such as fire, chemical leaks and business interruption due to damaged equipment. As noted above, OEF cannot typically be used to mitigate structural losses (e.g. building collapse).

When proposing the framework used here, Woo (2013) considered four actions for a period of heightened hazard in Emilia (northern Italy) in June 2012 (following the destructive earthquakes the month before). He proposed that: (1) the civil protection supplies could be restocked ( $C=1000$ euros and $\mathrm{L}=500,000$ euros); (2) the military and firefighters contingent in the area could be increased ( $C=5000$ and $L=1,000,000$ euros); (3) a rapid vulnerability map of the city of Ferrara could be created $(C=1,00$ euros and $L=1,000,000$ euros); and (4) all stocks of the Ferrara Nord petro-chemical complex could be removed ( $C=20,000$ euros, $L=20,000,000$ euros). The values of $L$ and $C$ for these actions, taken from Woo (2013), lead to $L / C$ ratios between 200 and 1000.

Other potential actions, grouped into categories depending on who would be responsible for taking/requiring the action, are given in Table 2. Field et al. (2016) provide a comprehensive discussion of the types of actions that could be triggered by OEF.

Four possible actions are considered in Table 3 to provide more guidance on the $L / C$ values to be used for the maps below. Because it is comprehensive, the main basis for potential actions is FEMA (2012)—all images come from that source. FEMA (2015) provide a very comprehensive set of illustrations of the importance of non-structural damage during the 2014 Napa earthquake in California. Non-structural components often contribute a large proportion of the costs of a building and its contents, e.g. Porter (2016) notes that they are on average about two-thirds of the total cost. Therefore, even if OEF cannot be used to mitigate major structural damage and associated deaths/injuries, if it can contribute to reducing non-structural losses, even by a small amount, this would be significant, especially when the actions are taken before occurrence of a mainshock. 


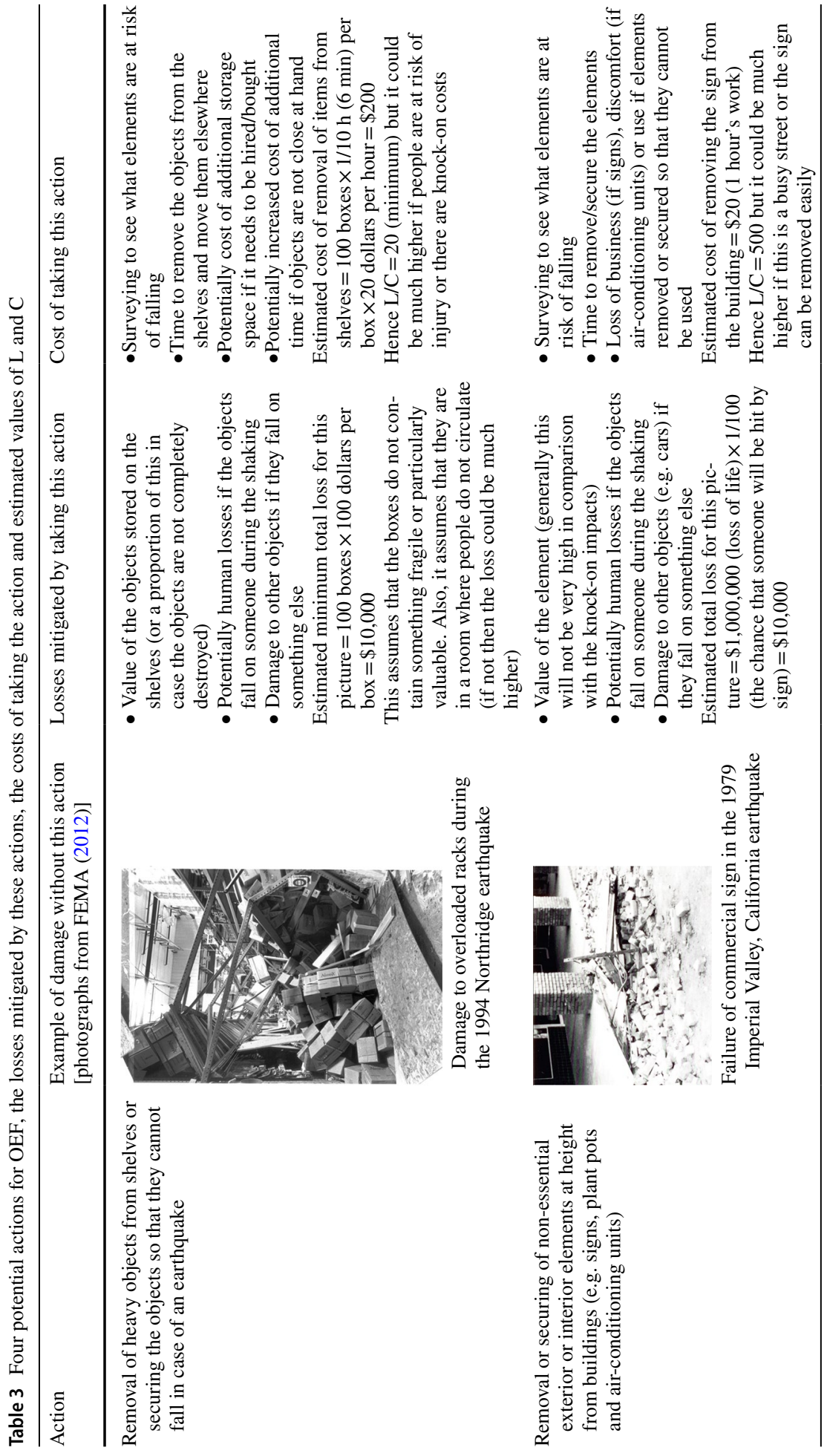




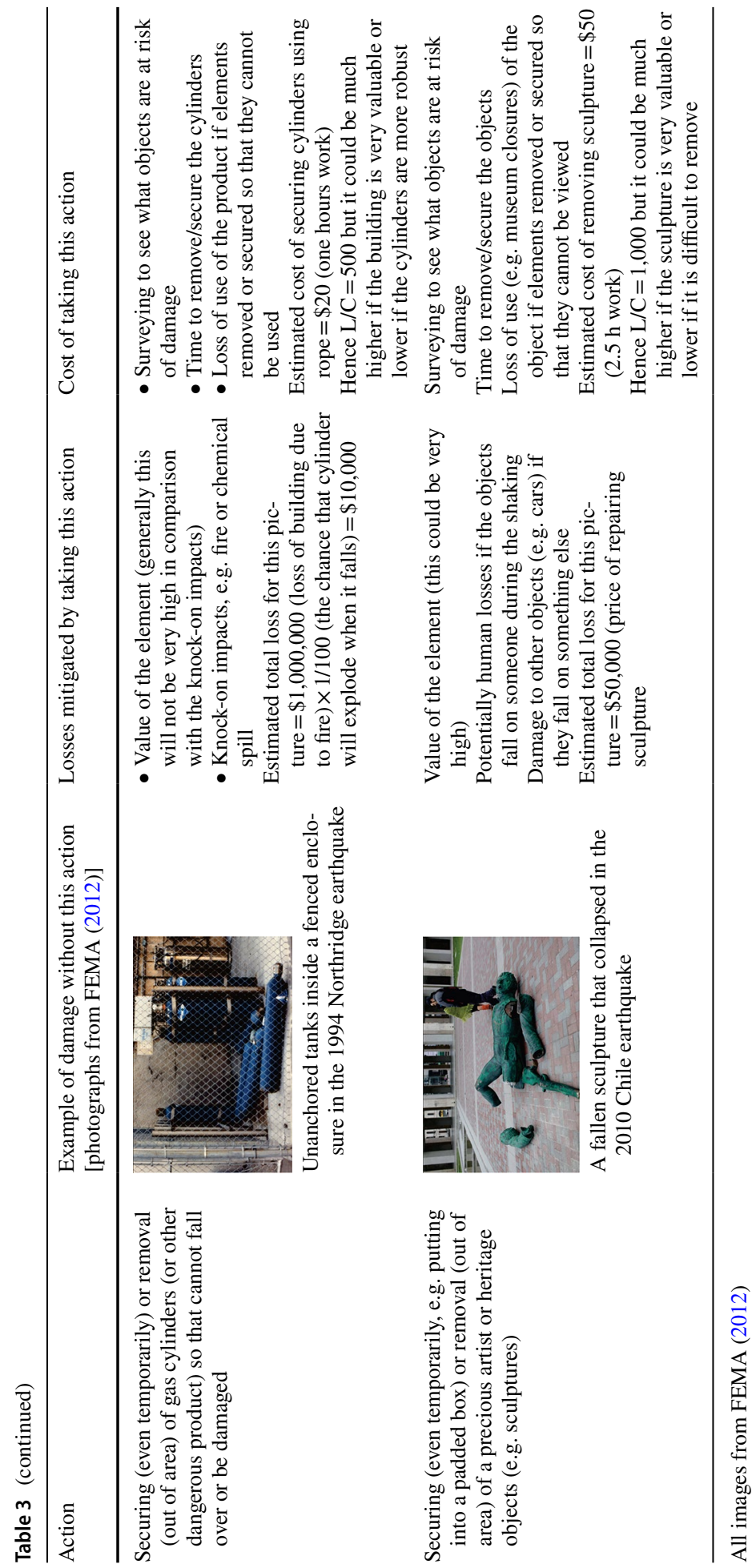


The list of losses mitigated and costs of the actions is given in Table 3; there is an estimate of the losses in terms of US dollars based on the photograph shown. Note that these estimates are rough as there is insufficient detail in the photograph to give a more accurate estimate. From these examples, $L / C$ ratios between 20 and 1000 can easily be justified.

\subsection{Assessment of the probability of surpassing the PGA threshold}

The assessment of $p$, the probability of surpassing the PGA threshold, is made using ESHM2013. The annual frequencies of exceedances for the considered PGA thresholds were assessed through spline interpolation of the hazard curves (in terms of logarithms) calculated using the ESHM2013 maps for all six available return periods (72, 102, 475, 975, 2475 and 4975 years). Extrapolation has been done for the points less than 72 or greater than 4975 years return period, using linear regression in logarithmic space from the two nearest data points.

Next, the annual frequencies of exceedance are converted to daily rates (dividing by 365) and from these $p$ is estimated, using the Poisson distribution, for the considered number of days, $d$. Because OEF is generally used to trigger actions during short periods when the chance of a damaging earthquake ground motions has increased (in this article due to increased seismicity prior to a mainshock), in the following only relatively low values for $d(\leq 30)$ are considered. The probability given using this method is the long-term (timeindependent) chance of surpassing the PGA threshold. Therefore, in the areas for which the considered action is shown to be cost-beneficial $(R>1)$ the action should be taken without any need for $O E F$, i.e. it is cost-beneficial for the time-independent seismic hazard of that area.

The potential utility of $\mathrm{OEF}$ is to trigger additional risk mitigation actions during periods of a heightened chance of a large earthquake. Therefore, in the following analyses increases in the time-independent probabilities obtained from ESHM2013 are considered by increasing $p$ by a factor called the "probability gain" hereafter. Because this study aims to provide general guidance on where and for which actions OEF may be cost-beneficial, how much $p$ can increase from its time-independent value is assessed using the available literature. In aftershock periods, the probability gain is a function of time since the mainshock (latency) as well as the forecasting duration (Field and Milner 2018). However, in this article we are assuming the probability gain to be constant because we are considering the period prior to a mainshock not the aftershock period. This assumption greatly simplifies the complexity of the problem, although it means that the results shown below potentially overestimate $\mathrm{R}$ as the probability gain likely decreases with time since the forecast of a mainshock.

There are a number of studies available in the literature that provide estimates of how much the probability of a potentially damaging earthquake increased during particular sequences. In this article, we are using the probability of potentially damaging ground motions (here PGA) rather than an earthquake itself to compute the benefit-to-cost ratio of different actions. The relationship between the probability an earthquake exceeding a particular size (e.g. moment magnitude 6) and the probability of PGA exceeding a threshold is not linear [e.g. Figure 3 of Douglas and Danciu (2020)], and hence, there is a potential difficulty in using the probability increases reported in the literature. For the relatively low daily probabilities and PGA thresholds considered here and given the large assumptions in other parts of the analysis, however, the slight nonlinearity in the relationship is ignored. Probabilistic seismic hazard analyses (PSHAs) for a single source zone of uniform 
seismicity following a Gutenberg-Richter law (Gutenberg and Richter 1945) and considering different long-term activity rates (see below), showed that assuming equality between an increase in the probability of an earthquake larger than a certain magnitude and the increase in the probability of a PGA larger than a certain threshold leads to an error that is negligible for the purposes of this analysis. The probability of certain level of ground motion (instead of earthquake probabilities) is easier to use for risk reduction purposes (e.g. Marzocchi et al. 2017, their Fig. 4).

Reported increases in daily probabilities of potentially damaging earthquakes range from about 20 times (Marzocchi et al. 2015) to roughly 1000 (Gulia et al. 2016; McBride et al. 2020). Jordan and Jones (2010) noted that the short-term earthquake probability (STEP) model that used to be deployed by USGS (Gerstenberger et al. 2005) often showed increases in probabilities of ground motions exceeding a Modified Mercalli Intensity of VI of 10-100 times [Gerstenberger et al. (2005) themselves showed a map with increases of up to 30 times in some parts of California]. The increase in weekly probability of intensity VII close to Norcia was reported to be about three orders of magnitude before the mainshock of 30th October 2016; hence, probability increases in potential ground shaking could be very high in some cases (Marzocchi et al. 2017). These observed increases in previous sequences will define the values considered when drawing the maps below. It is noted that all identified studies providing estimates of probability increases of either large earthquake occurrence or ground-motion exceedance are for highly seismically active areas such as Italy and California. Therefore, these large increases in probabilities may not be representative of all areas of Europe, including areas of low seismicity such as much of the north of the continent. There is insufficient research on this topic to know if potential probability gains in such areas prior to a mainshock are comparable to those in seismically more active areas. Earthquake catalogues in low-seismicity regions do not allow us due to their sparseness to distinguish those areas from more active areas concerning the size of any potential increase in probability.

In this article, the focus is on natural seismicity rather than seismicity induced by human actions (e.g. fluid injection, mining and dam impounding). Induced seismicity can lead to rapid increases in the probability of a potentially damaging earthquake occurring within a small area (e.g. Gupta and Baker 2019). The approach followed here could be applied to induced seismicity by using an appropriate value for the increase in the probability of an earthquake occurring, although it is unlikely that the assumption that the hazard curve shape remains the same would hold in the case of induced seismicity (induced events are likely to be biased towards smaller magnitudes than natural events, i.e. a larger $b$ value).

\section{Maps showing areas where actions are cost-beneficial}

To show the impact of the various input parameters and because of the large uncertainties in their assessment and how they vary for different actions and locations, a parametric analysis is conducted for this wide range of input parameters:

- The crisis duration $(d): 7$ days and 30 days (1 month);

- Loss-to-cost ratio $(L / C): 10,100,1,000$, and 10,000;

- The threshold PGA: $46 \mathrm{~cm} / \mathrm{s}^{2}$ (macroseismic intensity V), $84 \mathrm{~cm} / \mathrm{s}^{2}$ (macroseismic intensity VI), and $154 \mathrm{~cm} / \mathrm{s}^{2}$ (macroseismic intensity VII), where the approximate macroseismic intensities are from the relationship of Caprio et al. (2015); and 
- The probability gain, which indicates the factor by which the probability increases during the period of the OEF action (i.e. the crisis duration): 1 (no increase), 10, 100 and 1,000 .

As any triggered action should be cost-beneficial (i.e. $R$ must be greater than unity), in the maps in this section and the electronic supplement, the following ranges of $R$ are indicated: $R<1$ (not cost-beneficial), $R$ between 1 and 1.5 (marginally cost-beneficial), $R$ between 1.5 and 2.5 (moderately cost-beneficial), $R$ between 2.5 and 5 (clearly cost-beneficial) and $R>5$ (highly cost-beneficial).

The benefit-to-cost ratio results are shown in Fig. 1 in the case of $L / C=1000$, probability gain $=100$, threshold PGA $=46 \mathrm{~cm} / \mathrm{s}^{2}$ and for both $d=7$ and $d=30$ days. $L / C=1,000$ may seem like a high ratio as it suggests that mitigation only costs $0.1 \%$ of the total loss, but some actions discussed above would have such high ratios. A probability gain of 100 corresponds to a significant increase in the seismic hazard in the crisis duration period prior to a mainshock, which has been observed in past earthquake sequences (see above). As seen in Fig. 1, OEF is beneficial in the majority of Europe except in some parts in the north of the continent. This demonstrates that low-cost actions are clearly beneficial, especially when the hazard increases significantly in a short time period.

For the longer crisis period (30 days), the OEF actions are even more cost-beneficial as seen in Fig. 1 by comparing the maps for 7 and 30 days, e.g. OEF is marginally/moderately/clearly cost-beneficial in the south of the UK and parts of Norway in the case of $d=7$ days, but it becomes highly cost-beneficial when the crisis duration increases to 30 days. Maps for the various combinations of $d, L / C$, threshold PGA, and probability gains are shown in 96 maps in the electronic supplement, where each page shows 16 maps and the L/C ratio increases from top to bottom $(10$ to 10,000$)$, and the probability gain increases from left to right (1 to 1000). In the case of no or small probability gain and expensive actions (e.g. $L / C=10$ ), OEF is not cost-beneficial. When either the seismic hazard increases significantly or large $L / C$ ratios are considered, OEF becomes cost-beneficial (highly cost-beneficial in some cases). The maps in the electronic supplement also show that, as expected, the highest OEF benefits are obtained for the lowest threshold PGA (i.e. $46 \mathrm{~cm} / \mathrm{s}^{2}$ ). One interpretation would be the actions for mitigating secondary systems are beneficial for OEF. The maps in the electronic supplement also show that, everything else being equal, actions are more justifiable for long crisis periods (30 days) than for short crisis periods (7 days).

\section{Nomogram for quick calculations of benefit-to-cost ratios}

Nomograms (e.g. Levens 1959) are graphical tools that allow complex equations to be evaluated to high accuracy simply using a print-out of the nomogram and a straight edge. They were common in many fields of science and engineering in the era before digital computers became ubiquitous, i.e. up until the 1980s, as they reduced the likelihood of computational errors. As argued by Douglas and Danciu (2020), who present a nomogram summarising the results of simple PSHAs, nomograms are still potentially useful as they visually present the connections among the variables within an equation and allow the sensitivity of the results to changes in those variables to be assessed quickly. In this section, a nomogram for the simple cost-benefit analyses for OEF is presented. 

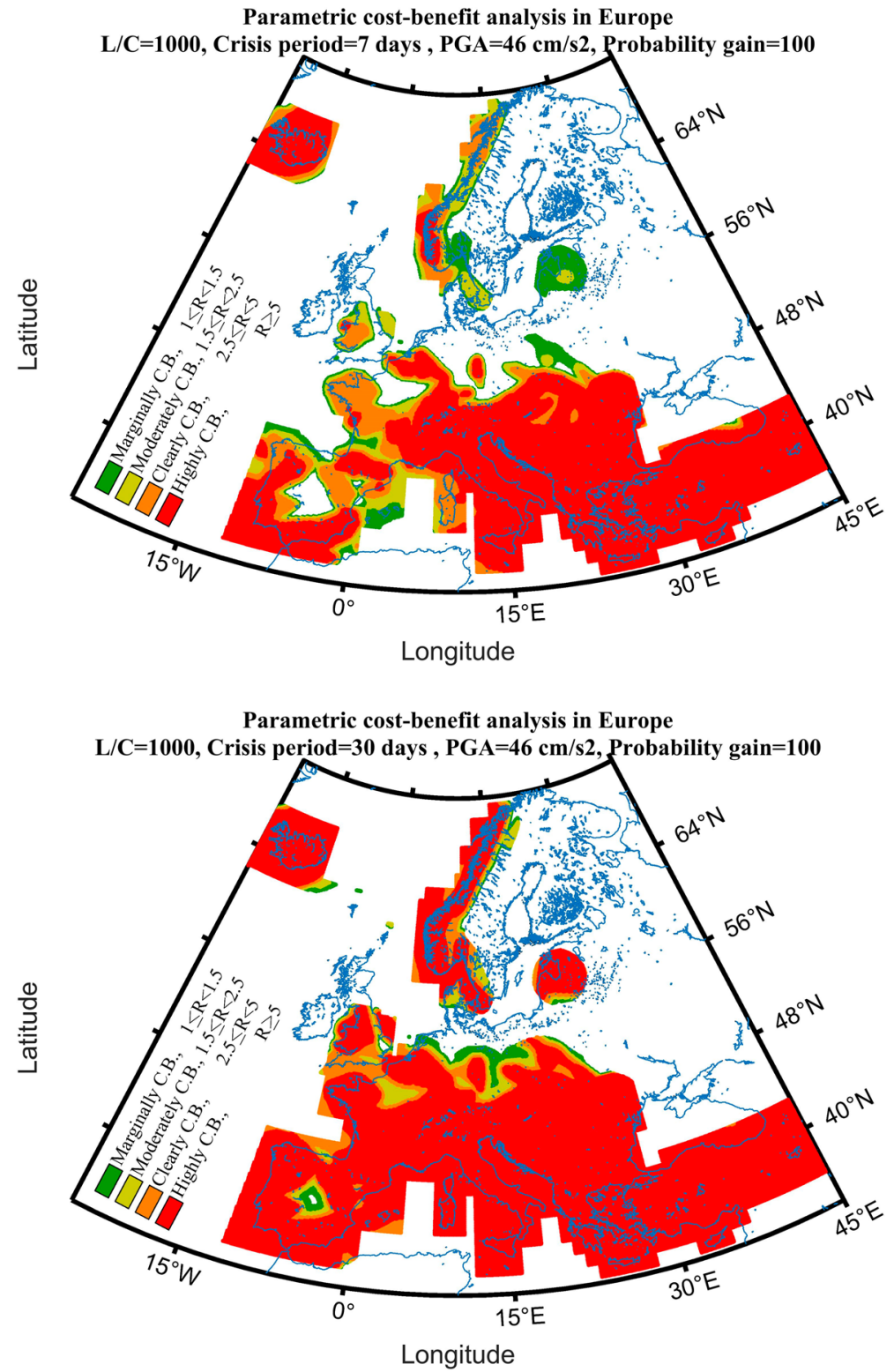

Fig. 1 Cost-benefit analysis assuming $L / C=1000$, Probability gain $=100$ and threshold PGA $=46 \mathrm{~cm} / \mathrm{s}^{2}$. $d=7$ days in the top figure and $d=30$ days in the bottom figure

The nomogram presents the relations between five variables: threshold PGA (in g), daily probability of an earthquake of moment magnitude 4 or larger, the number of days for which the OEF action is taken $(d)$, the ratio of the loss mitigated to the cost of the OEF action $(L / C)$ and the benefit-to-cost ratio $(R)$. The nomogram was created using the 
open-source pynomo software ${ }^{1}$ using a type 3 nomogram that consists of five parallel vertical axes. Note that one advantage of a nomogram over normal graphs is that any variable of the equation can be the subject, i.e. in this case the value of any of the five variables can be found given the other four. Before presenting the final nomogram, the steps followed to construct it are briefly described.

Following the success of Douglas and Danciu (2020) in deriving a nomogram for PSHA, a similar approach was followed here. The first step was to evaluate the daily frequencies of exceedance of three potential PGA thresholds: $0.05 \mathrm{~g}, 0.1 \mathrm{~g}$ and $0.2 \mathrm{~g}$ for the OEF actions for different daily probabilities of earthquakes of moment magnitude 4 or larger. These frequencies were calculated using PSHA of a circular area of radius $100 \mathrm{~km}$ of uniform seismicity defined by a Gutenberg-Richter relationship (Gutenberg and Richter 1945) with $b=1$, nine activity rates and maximum magnitude of 8 , coupled with the Cauzzi and Faccioli (2008) PGA ground-motion model, which is one of the two highest weighted ground-motion models in the logic tree for crustal earthquakes used to derive ESHM2013 (Delavaud et al. 2012). The Poisson distribution was then used to convert the frequencies of exceedance to daily probabilities.

The result was the daily probabilities of exceeding the three threshold PGAs for nine daily earthquake probabilities. Using the common assumption of a power law to approximate the hazard curve, which Douglas and Danciu (2020) showed works very well for simple PSHAs, linear equations were derived between the logarithms of the PGA thresholds and their corresponding probabilities of exceedance for each of the daily earthquake probabilities considered. It was found that the slope of these linear equations was almost the same for all earthquake probabilities but that the intercept changed. This intercept could be itself expressed as a linear function of the daily earthquake probabilities. The result of these steps is a function connecting the daily probability of occurrence of an earthquake of magnitude 4 or larger (for any value between $0.0087 \%$ and 58\%) and the corresponding daily probability of exceeding any PGA value between $0.05 \mathrm{~g}$ and $0.2 \mathrm{~g}$.

Because the daily probabilities of exceeding the PGA thresholds considered are all lower than $1 \%$, it was assumed that the probability of exceeding the threshold within a period of days (up to 30 days, i.e. a month) was simply the daily probability multiplied by the number of days (note that this is different to the analysis presented above where the Poisson distribution was used). This is not mathematically correct as the Poisson distribution should be invoked (as it was to construct the maps shown above), but the error introduced by this assumption is low, and it allows the equation for the benefit-to-cost ratio to expressed as a linear function in terms of logarithms (in order to convert from a product), i.e.:

$$
\ln R=\ln d+\ln p_{G M}+\ln L / C,
$$

where $\ln p_{G M}$ is the logarithm of the daily probability of exceeding the threshold PGA, which itself (given the previous step) is a linear function of the logarithm of the daily probability of an earthquake of moment magnitude 4 or larger occurring.

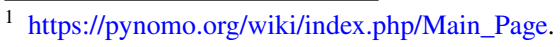


Through these steps, it is possible to express $R$ in the form required for a type 3 nomogram, i.e.:

$$
f(R)+f(d)+f\left(p_{E}\right)+f(y)+f\left(\frac{L}{C}\right)=0,
$$

where $y$ is the threshold PGA considered for the action. It is possible to consider $L$ and $C$ as two separate variables, but it was decided that this would complicate the use of the nomogram without much benefit as often it is easier to consider the ratio $L / C$ rather than use the individual components.

The resulting nomogram is shown in Fig. 2 with an isopleth (red dotted line) drawn for a threshold PGA of $0.05 \mathrm{~g}$, a daily probability of a moment magnitude 4 or larger earthquake occurring of $4 \%$, a week-long OEF action (i.e. $d=7$ days) and an $L / C$ of 1000 . This leads to an $R$ of about 3.5 , i.e. the action is highly cost-beneficial. To use this nomogram, values on the five vertical principal axes should be connected by straight lines via the two vertical secondary axes (labelled $R_{1}$ and $R_{2}$ ).

\section{Conclusions}

Areas of high seismic hazard (e.g. Iceland, Italy, Greece and Turkey) will benefit from OEF prior to a mainshock if there are low-cost (cost ratios $<0.1 \%$ ) short-term mitigation actions that can be performed even if the increase in the weekly probability of an earthquake is moderate. Considering the return period of the PGAs that could cause losses, the actions would be triggered sufficiently often (more frequently than every 10 to 50 years) for the local population to have prior experience of what actions to take. Areas of moderate seismic hazard (e.g. Alps, Pyrenees, Rhine graben and south Spain) would only benefit from OEF prior to a mainshock in the case of very large increases in weekly probabilities and only if low-cost actions are possible (and the triggers would likely occur infrequently, i.e. less often than once every 50 years). If the crisis period (heightened hazard) goes on for a number of weeks, more expensive actions become cost-beneficial. If actions can mitigate losses that are caused by low-amplitude ground motions, then these actions are more cost-beneficial than actions related to losses caused by stronger earthquake shaking because low-amplitude ground motions occur much more frequently.

It could be that even if $R$ was less than unity for a given action (i.e. it is not assessed as being cost-beneficial) that the action may be taken by some people if it was sufficiently cheap (low $C$ ) or easy to do. For example, there is a personal cost of some risk mitigation actions in day-to-day life (e.g. keeping a well-stocked first aid cabinet) that may not be cost-beneficial given the chance that it is required, but the cost to most people is sufficiently low that this cost is not a barrier to choosing this action.

In conclusion, despite the considerable assumptions made, the results of the simple cost-benefit analyses presented here show that short-term OEF has the potential to trigger cost-beneficial actions before occurrence of a mainshock over much of Europe, especially if low-cost actions (cost ratios $<0.1 \%$ ) are identified for an element at risk. 
Thres. PGA (g) Daily prob. M $\geq 4$

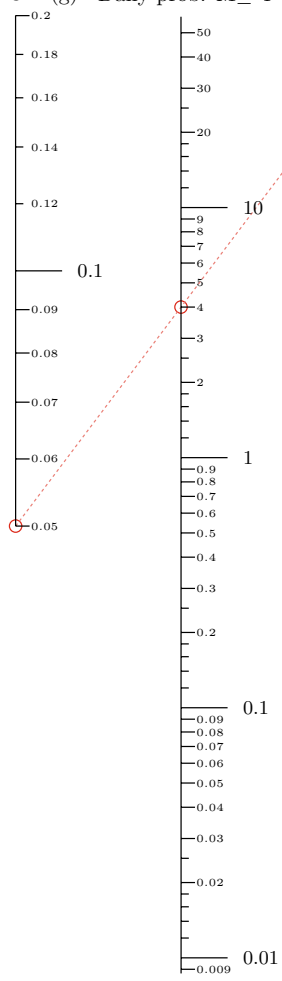

$\mathrm{R}_{1}$

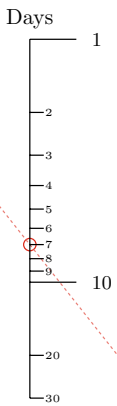

$\mathrm{R}_{2}$

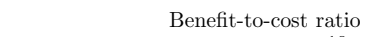

-

$-7$

$-6$

Loss mitigated/Cost

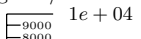

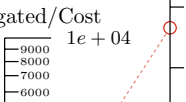

$-5000$

$-4000$

$E^{-3000}$

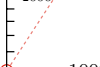

1000

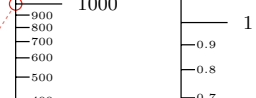

$-400$

$-300$

$-20$

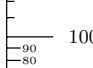

100

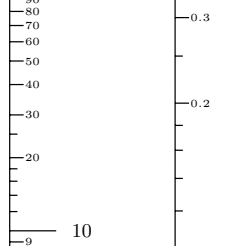

$E_{-7}^{9}$

${ }_{-5}^{-6}$

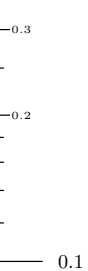

0.1

Fig. 2 The nomogram developed for cost-benefit analysis of OEF actions. An isopleth (red dotted line) is shown for an example application for a threshold PGA of $0.05 \mathrm{~g}$ (left-most axis), a daily probability of an earthquake of magnitude $\geq 4$ of $4 \%$, a week-long (7 days) OEF action and a L/C ratio of 1000 leading to $R=3.5$ (right-most axis) 
Acknowledgements We thank partners of Workpackage 3 of TURNkey and the project management team for their comments on these analyses. We also thank E. H. Field and an anonymous reviewer for their valuable and constructive comments which helped to improve the article.

Funding This study was funded by the European Union's Horizon 2020 research and innovation programme under grant agreement No 821046, project TURNkey (Towards more Earthquake-resilient Urban Societies through a Multi-sensor-based Information System enabling Earthquake Forecasting, Early Warning and Rapid Response actions).

\section{Compliance with ethical standards}

Conflict of interests The authors have no conflicts of interest to declare that are relevant to the content of this article.

Open Access This article is licensed under a Creative Commons Attribution 4.0 International License, which permits use, sharing, adaptation, distribution and reproduction in any medium or format, as long as you give appropriate credit to the original author(s) and the source, provide a link to the Creative Commons licence, and indicate if changes were made. The images or other third party material in this article are included in the article's Creative Commons licence, unless indicated otherwise in a credit line to the material. If material is not included in the article's Creative Commons licence and your intended use is not permitted by statutory regulation or exceeds the permitted use, you will need to obtain permission directly from the copyright holder. To view a copy of this licence, visit http://creativecommons.org/licenses/by/4.0/.

\section{References}

Baker JW, Bradley BA (2017) Intensity measure correlations observed in the NGA-West2 database, and dependence of correlations on rupture and site parameters. Earthquake Spectra 33(1):145-156

Brooks EM, Diggory M, Gomez E, Salaree A, Schmid M, Saloor N, Stein S (2016) Should Fermi have secured his water heater?. Seismol Res Lett 87(2A):387-394

Caprio M, Tarigan B, Worden CB, Wiemer S, Wald DJ (2015) Ground Motion to Intensity Conversion Equations (GMICEs): a global relationship and evaluation of regional dependency. Bull Seismoll Soc Am 105(3):1476-1490. https://doi.org/10.1785/0120140286

Cauzzi C, Behr Y, Guenan TL, Douglas J, Auclair S, Woessner J, Clinton J, Wiemer S (2016) Earthquake early warning and operational earthquake forecasting as real-time hazard information to mitigate seismic risk at nuclear facilities. Bull Earthquake Eng 14(9):2495-2512. https://doi.org/10.1007/s1051 8-016-9864-0

Cauzzi C, Faccioli E (2008) Broadband (0.05 to 20 s) Prediction of displacement response spectra based on worldwide digital records. J Seismol 12(4):453.

Copenhagen Consensus Center (2012) Copenhagen Consensus Center. Copenhagen Consensus 2012.

Christophersen A, Rhoades DA, Gerstenberger MC, Bannister S, Becker J, Potter SH, McBride S (2017) Progress and challenges in operational earthquake forecasting in New Zealand. 2017 NZSEE Conference, September 9. https://db.nzsee.org.nz/2017/O3C.4_Christophersen.pdf.

Delavaud E, Cotton F, Akkar S, Scherbaum F, Danciu L, Beauval C, Drouet S et al (2012) Toward a groundmotion logic tree for probabilistic seismic hazard assessment in Europe. J Seismol 16(3):451-473

Douglas J, Danciu L (2020) Nomogram to help explain probabilistic seismic hazard. J Seismol 24(1):221228. https://doi.org/10.1007/s10950-019-09885-4

FEMA (2012) Reducing the risks of nonstructural earthquake damage a practical guide, FEMA E-74. https ://www.fema.gov/fema-e-74-reducing-risks-nonstructural-earthquake-damage.

FEMA (2015) Performance of buildings and nonstructural components in the 2014 South Napa Earthquake, FEMA P-1024. https://www.fema.gov/media-library-data/1427861387880-3ea85f352f1de10c7e07 edf9ed561e7f/FEMAP-1024.pdf.

Field EH, Jordan TH, Jones LM, Michael AJ, Blanpied ML, Abrahamson N, Ackerman S et al (2016) The potential uses of operational earthquake forecasting. Seismol Res Lett 87(2A):313-322. https://doi. org/10.1785/0220150174

Field EH, Milner KR (2018) Candidate products for operational earthquake forecasting illustrated using the HayWired planning scenario, including one very quick (and Not-so-Dirty) hazard-map option. Seismol Res Lett 89(4):1420-1434 
Fiore A, Vanzi I, Nuti C, Demartino C, Greco R, Briseghella B (2019) To compute or not to compute?. J Traffic Transportation Eng (English Edition) 6(1):85-93. https://doi.org/10.1016/j.jtte.2018.07.001

Fischhoff B (2015) The realities of risk-cost-benefit analysis. Science 350(6260).

Gerstenberger MC, Wiemer S, Jones LM, Reasenberg PA (2005) Real-time forecasts of tomorrow's earthquakes in California. Nature 435(7040):328-331. https://doi.org/10.1038/nature03622

Ghesquiere F, Mahul O, Jamin L (2006) Earthquake vulnerability reduction program in Colombia: a probabilistic cost-benefit analysis. The World Bank. Policy Research Working Paper No. 3939

Giardini D, Woessner J, Danciu L, Crowley H, Cotton F, Grünthal G, Pinho R et al (2013) Seismic Hazard Harmonization in Europe (SHARE): online data resource. Serv ETH Zurich Switz, Swiss Seism

Gkimprixis A, Tubaldi E, Douglas J (2019) Comparison of methods to develop risk-targeted seismic design maps. Bull Earthquake Eng 17(7):3727-3752

Godschalk DR, Rose A, Mittler E, Porter K, West CT (2009) Estimating the value of foresight: aggregate analysis of natural hazard mitigation benefits and costs. J Enviro Plan Manage 52(6):739-756

Gulia L, Tormann T, Wiemer S, Herrmann M, Seif S (2016) Short-term probabilistic earthquake risk assessment considering time-dependent b values. Geophys Res Lett 43(3):1100-1108

Gupta A, Baker JW (2019) A framework for time-varying induced seismicity risk assessment, with application in Oklahoma. Bull Earthquake Eng 17(8):4475-4493. https://doi.org/10.1007/s10518-019-00620 $-5$

Gutenberg B, Richter FC (1945) Frequency of earthquakes in California. Nature 156(3960):371. https:// doi.org/10.1038/156371a0

Hallegatte S (2012) A cost effective solution to reduce disaster losses in developing countries. Hydrometeorological services, early warning, and evacuation. World Bank Policy Research Working Paper, no. May 22. https://doi.org/10.1596/1813-9450-6058.

Holden R, Lee R, Reichle M (1989) Technical and economic feasibility of an earthquake early warning system in California, Report to the California Legislature, California Division of Mines and Geology

Hugenbusch D, Neumann T (2016) Cost-benefit analysis of disaster risk reduction: a synthesis for informed decision making. Aktion Deutschland Hilft.

Iervolino I, Chioccarelli E, Giorgio M, Marzocchi W, Zuccaro G, Dolce M, Manfredi G (2015) Operational (short-term) earthquake loss forecasting in Italy. Bull Seismol Soc Am 105(4):2286-2298. https://doi.org/10.1785/0120140344

Jordan TH, Marzocchi W, Michael AJ, Gerstenberger MC (2014) Operational earthquake forecasting can enhance earthquake preparedness. Seismol Res Lett 85(5):955-959. https://doi.org/10.1785/02201 40143

Jordan TH, Chen YT, Gasparini P, Madariaga R, Main I, Marzocchi W, Papadopoulos G, Sobolev G, Yamaoka K, Zschau J (2011) Operational earthquake forecasting: state of knowledge and guidelines for utilization. Ann Geophys 54(4):319-391. https://doi.org/10.4401/ag-5350

Jordan TH, Jones LM (2010) Operational earthquake forecasting: some thoughts on why and how. Seismol Res Lett 81(4):571-574. https://doi.org/10.1785/gssrl.81.4.571

Kunreuther H, Michel-Kerjan E (2012) Challenge paper: natural disasters. Copenhagen Consensus.

Levens AS (1959) Nomography. Wiley, New York

Liel AB, Deierlein GG (2013) Cost-benefit evaluation of seismic risk mitigation alternatives for older concrete frame buildings. Earthquake Spectra 29(4):1391-1411

Marzocchi W, Lombardi AM, Casarotti E (2014) The establishment of an operational earthquake forecasting system in Italy. Seismol Res Lett 85(5):961-969. https://doi.org/10.1785/0220130219

Marzocchi W, Woo G (2009) Principles of volcanic risk metrics: theory and the case study of Mount Vesuvius and Campi Flegrei, Italy. J Geophys Res Solid Earth. https://doi.org/10.1029/2008JB0059 08

Marzocchi W, Iervolino I, Giorgio M, Falcone G (2015) When is the probability of a large earthquake too small? Seismol Res Lett 86(6):1674-1678

Marzocchi W, Taroni M, Falcone G (2017) Earthquake forecasting during the complex Amatrice-Norcia seismic sequence. Sci Adv 3(9):1-8. https://doi.org/10.1126/sciadv.1701239

McBride SK, Llenos AL, Page MT, Van Der Elst N (2020) \# EarthquakeAdvisory: exploring discourse between Government officials, news media, and social media during the 2016 Bombay Beach Swarm. Seismol Res Lett 91(1):438-451. https://doi.org/10.1785/0220190082

Mechler R (2016) Reviewing estimates of the economic efficiency of disaster risk management: opportunities and limitations of using risk-based cost-benefit analysis. Nat Hazards 81(3):2121-2147

Peresan A, Kossobokov VG, Panza GF (2012) Operational earthquake forecast/prediction. Rendiconti Lincei 23(2):131-138. https://doi.org/10.1007/s12210-012-0171-7 
Plag HP, Stein S, Brocklebank S, Jules-Plag S, Campus P (2014) Extreme geohazards: reducing disaster risk and increasing resilience. A Community Science Position Paper, ESF, GHCP and Group on Earth Observations

Porter K (2016) Not safe enough: the case for resilient seismic design. In: Proceedings of 2016 SEAOC Convention, pp 12-15.

Sellnow DD, Iverson J, Sellnow TL (2017) The evolution of the operational earthquake forecasting community of practice: the L'Aquila communication crisis as a triggering event for organizational renewal. J Appl Commun Res 45(2):121-139. https://doi.org/10.1080/00909882.2017.1288295

Smyth AW, Altay G, Deodatis G, Erdik M, Franco G, Gülkan P, Kunreuther H et al (2004) Probabilistic benefit-cost analysis for earthquake damage mitigation: evaluating measures for apartment houses in Turkey. Earthquake Spectra 20(1):171-203

Strauss JA, Allen RM (2016) Benefits and costs of earthquake Early warning. Seismol Res Lett 87(3):765-772. https://doi.org/10.1785/0220150149

Van Stiphout T, Wiemer S, Marzocchi W (2010) Are short-term evacuations warranted? Case of the 2009 L'Aquila Earthquake. Geophys Res Lett 37(6). https://doi.org/10.1029/2009g1042352.

Wanigarathna N, Yarovaya L (2018) Deliverable D5. 3 Community resilience and cost/benefit modelling: socio-technical-economic impact on stakeholder and wider vommunity. Liquefact project, H2020-DRA-2015

Wei HH, Skibniewski MJ, Shohet IM, Shapira S, Aharonson-Daniel L, Levi T, Salamon A, Levy R, Levi O (2014) Benefit-cost analysis of the seismic risk mitigation for a region with moderate seismicity: the case of Tiberias, Israel. Procedia Eng 85:536-542

Woessner J, Laurentiu D, Giardini D, Crowley H, Cotton F, Grünthal G, Valensise G et al (2015) The 2013 European seismic hazard model: key components and results. Bull Earthquake Eng 13(12):3553-3596. https://doi.org/10.1007/s10518-015-9795-1

Woo G (2013) Deliverable D6. 3 Guidelines to establish quantitative protocols for decision-making in operational earthquake forecasting. REAKT Project

Woo G (2010) Operational earthquake forecasting and risk management. Seismol Res Lett 81(5):778-782. https://doi.org/10.1785/gssrl.81.5.778

Woo G (2015) Cost-benefit analysis in volcanic risk. Volcanic hazards, risks and disasters. Elsevier, Amsterdam, pp 289-300

Publisher's Note Springer Nature remains neutral with regard to jurisdictional claims in published maps and institutional affiliations. 